\title{
Pengawasan Pelaksanaan Sistem Outsourcing yang Berbasis Pada Hak Asasi Manusia
}

\author{
Solechan \\ Fakultas Hukum, Universitas Diponegoro \\ solechan@live.undip.ac.id
}

\begin{abstract}
This study aims to find out, First, knowing the conditions of labor inspection; Second, knowing the efforts to optimize the supervision of outsourcing systems oriented to human rights. This method of writing scientific papers uses the writing of juridical-normative law, with a statutory approach. The results of writing indicate that: First, enforcement of labor law is not optimal. It is known from the existence of problems that occur, among others, the absence of social security, very low wages and the placement of outsourced workers who are not in accordance with the laws and regulations make outsourcing workers lose their basic rights. Second, efforts to optimize the supervision of outsourcing systems oriented to human rights can be done through the enforcement of integrated labor law. Supervision of the outsourcing system must emphasize protection (to protect), fulfillment (to fulfill), and respect to be more optimal. Therefore, concrete steps are needed in the enforcement of labor law. One of them is the establishment of a complaint center specifically centered at the Ministry of Manpower and integrated with the provincial level Manpower and Transmigration Office. This call center serves complaints about violations and is expected to improve the performance of labor inspectors.
\end{abstract}

Keywords: Supervision, Outsourcing System, Human Rights

\begin{abstract}
Abstrak
Penelitian ini bertujuan untuk mengetahui, Pertama, mengetahui kondisi pengawasan bidang ketenagakerjaan; Kedua, mengetahui upaya optimalisasi pengawasan sistem outsourcing yang berorientasi pada Hak Asasi Manusia. Metode penulisan karya tulis ilmiah ini menggunakan penulisan hukum yuridis-normatif, dengan pendekatan statutory approach. Hasil penulisan menujukan bahwa: Pertama, penegakan hukum ketenagakerjaan belum optimal. Hal tersebut diketahui dari masih adanya persoalan-persoalan yang terjadi antara lain tidak adanya jaminan sosial, upah yang sangat rendah dan penempatan tenaga kerja outsourcing yang tidak sesuai dengan peraturan perundang-undangan menjadikan tenaga kerja outsourcing kehilangan hak-hak dasarnya. Kedua, upaya optimalisasi pengawasan sistem outsourcing yang berorientasi pada Hak Asasi Manusia dapat dilakukan melalui penegakan hukum ketenagakerjaan terpadu. Pengawasan sistem outsourcing harus menekankan pada perlindungan (to protect), pemenuhan (to fulfill), dan penghormatan (to respect) agar lebih optimal. Oleh karena itu, diperlukan langkah konkret dalam penegakan hukum ketenagakerjaan. Salah satunya dengan pembentukan call center khusus pengaduan yang terpusat di Kementerian Ketenagakerjaan dan terintegrasi dengan Dinas Tenaga Kerja dan Transmigrasi tingkat provinsi. Call center ini melayani pengaduan atas terjadinya pelanggaran dan diharapkan dapat meningkatkan kinerja pengawas ketenagakerjaan.
\end{abstract}

Kata Kunci: Pengawasan, Sistem Outsourcing, Hak Asasi Manusia 


\section{A. Pendahuluan}

Hukum Ketenagakerjaan adalah bagian dari hukum berkenaan dengan pengaturan hubungan ketenagakerjaan baik bersifat perseorangan maupun kolektif. ${ }^{1}$ Hukum Ketengakerjaan di Indonesia telah diatur dalam Undang-Undang Nomor 13 Tahun 2003 tentang Ketenagakerjaan, yang selanjutnya akan disebut UU Ketenagakerjaan. UU Ketenagakerjaan merupakan suatu landasan yuridis dalam dunia ketenagakerjaan yang mengatur ketentuan-ketentuan berupa hak dan kewajiban bagi pengusaha dan pekerja. Ketentuan-ketentuan yang diatur di antaranya penempatan tenaga kerja ${ }^{2}$, penggunaan tenaga kerja asing $^{3}$, pengupahan ${ }^{4}$, pemutusan hubungan kerja ${ }^{5}$ dan pengawasan $^{6}$.

Selain itu, UU Ketenagakerjaan pun mengatur ketentuan outsourcing untuk pertama kalinya. Sistem outsourcing yang dikenal pula dengan istilah alih daya merupakan terobosan baru dalam dunia ketenagakerjaan dengan menawarkan efisiensi biaya produksi (cost of production) bagi pengusaha. Dengan menggunakan sistem outsourcing ini, pihak perusahaan berusaha untuk menghemat pengeluaran dalam membiayai sumber daya manusia (SDM) yang bekerja di perusahaan yang bersangkutan. ${ }^{7}$ Ketentuan mengenai sistem outsourcing diatur pada Pasal 64 - Pasal 66. Pasal 64 mengatur mengenai bentuk hubungan kerja, Pasal 65 mengatur mengenai syarat-syarat pelaksanaan kerja yang melindungi pekerja serta Pasal 66 mengatur mengenai jenis dan sifat pekerjaan yang dapat dilakukan dengan perjanjian pemborongan kerja atau penyediaan jasa pekerja. ${ }^{8}$ Namun, ketentuan tersebut diragukan oleh sebagian masyarakat dibuktikan dengan diajukannya judicial review ke Mahkamah Konstitusi sebanyak dua kali. Pengujian pertama diputus dengan amar ditolak untuk seluruhnya atas ketentuan outsourcing sebagaimana Putusan Mahkamah Konstitusi Nomor Perkara 012/PUU-I/2003. Pengujian kedua diputus dengan amar dikabulkan sebagian atas Pasal 65 ayat (7) dan Pasal 66 ayat (2) huruf b sebagaimana Putusan Mahkamah Konstitusi Nomor Perkara 27/PUU-IX/2011. Dengan adanya

\footnotetext{
1 Agusmidah dkk, Bab-Bab Tentang Hukum Perburuhan Indonesia, Denpasar: Pustaka Larasan; Jakarta: Universitas Indonesia; Universitas Leiden; Universitas Groningen, 2012, hlm. 1.

${ }^{2}$ Lihat Pasal 31 - Pasal 38 Undang- Undang Nomor 13 Tahun 2003 tentang Ketenagakerjaan.

${ }^{3}$ Lihat Pasal 42 - Pasal 49 Undang-Undang Nomor 13 Tahun 2003 tentang Ketenagakerjaan.

${ }^{4}$ Lihat Pasal 88 - Pasal 98 Undang-Undang Nomor 13 Tahun 2003 tentang Ketenagakerjaan.

${ }^{5}$ Lihat Pasal 150 - Pasal 172 Undang-Undang Nomor 13 Tahun 2003 tentang Ketenagakerjaan.

${ }^{6}$ Lihat Pasal 176 - Pasal 181 Undang-Undang Nomor 13 Tahun 2003 tentang Ketenagakerjaan.

${ }^{7}$ Adrian Sutedi, "Hukum Perburuhan, Jakarta: Sinar Grafika, 2009, hlm. 217.

8 Susilo Andi Darma, Kajian Hukum Ketenagakerjaan Terhadap Peraturan Menteri Tenaga Kerja dan Transmigrasi Nomor 19 Tahun 2012”, Volume 26, Tahun 2014, hlm. 252.
} 
putusan kedua tersebut, ketentuan pada Pasal 65 ayat (7) dan Pasal 66 ayat (2) huruf b tidak diberlakukan lagi.

Belakangan ini, sistem outsourcing merupakan tren baru di kalangan masyarakat. Namun, implementasi sistem outsourcing ini masih menuai beragam persoalan. Berdasarkan pernyataan Irianto Simbolon, Direktur Jenderal Pembinaan Hubungan Industrial dan Jaminan Sosial Kementerian Ketenagakerjaan, diketahui bahwa terdapat 12 perusahaan milik negara yang tidak tepat dalam mempekerjakan tenaga kerja outsourcing sepanjang tahun 2015. ${ }^{9}$ Padahal, telah tegas dinyatakan bahwa bidang pekerjaan yang diperbolehkan hanya terbatas pada usaha pelayanan kebersihan (cleaning service), usaha penyediaan makanan bagi pekerja/buruh (catering), usaha tenaga pengaman (security), usaha jasa penunjang di pertambangan dan perminyakan serta usaha penyediaan angkutan bagi pekerja/buruh. ${ }^{10}$

Fakta di lapangan menunjukan bahwa masih adanya pekerja outsourcing yang digaji di bawah Upah Minimum Regional, salah satunya Yanti Nunun, cleaning service di wilayah Serpong, Tangerang Selatan. Pada tahun 2012, beliau digaji Rp 1.050.000,00 tiap bulan sedangkan Upah Minimum Kota Tangerang Selatan saat itu sebesar Rp 1.529.150 per bulan. Di tahun yang sama, hal senada terjadi pada Marianus, cleaning service di bilangan Jakarta Utara. Tiap bulan beliau digaji Rp 1.000.000,00 sedangkan Upah Minimum Provinsi DKI Jakarta saat itu sebesar Rp 1.529.150 per bulan. ${ }^{11}$

Persoalan-persoalan tersebut terjadi karena belum berfungsinya pengawasan secara optimal. Muhaimin Iskandar, mantan Menteri Tenaga Kerja dan Transmigrasi, menyatakan bahwa sepanjang tahun 2012 jumlah pengawas ketenagakerjaan sebanyak 1.469 orang yang tersebar di seluruh Indonesia dengan jumlah perusahaan yang harus diawasi sejumlah 224.060 perusahaan. Padahal, kebutuhan ideal pengawas ketenagakerjaan dengan rasio 60 perusahaan per tahun, dibutuhkan sebanyak 3.734 pengawas ketenagakerjaan. Selain itu, sebaran pengawas ketenagakerjaan baru

\footnotetext{
9 Raisa Adila, "Menteri Hanif Serius Tangani Outsourcing di BUMN", http://economy.okezone.com/read/2015/06/24/320/1170781/menteri-hanif-serius-tangani-outsourcing-dibumn, diakses pada 11 Oktober pukul 1.17 WIB.

${ }^{10}$ Lihat Pasal 17 ayat (3) Peraturan Menteri Tenaga Kerja dan Transmigrasi Nomor 19 Tahun 2012 tentang Syarat-Syarat Penyerahan Sebagian Pelaksanaan Pekerjaan Kepada Peusahaan Lain.

11 Siprianus Edi Hardum, "Sistem Kerja Outsourcing Perlu Pengawasan Ketat", http://sp.beritasatu.com/ekonomidanbisnis/sistem-kerja-outsourcing-perlu-pengawasan-ketat/24402, diakses pada 11 Oktober 2016 pukul 08.37 WIB.
} 
menjangkau lebih kurang 300 kabupaten/kota dari sekitar 497 kabupaten/kota. ${ }^{12}$ Selain itu, pengawasan sistem outsourcing seharusnya menekankan pada perlindungan (to protect), pemenuhan (to fulfill), dan penghormatan (to respect) agar selaras dengan fungsi Hak Asasi Manusia.

Berkaca pada fakta empiris dan normatif yang telah penulis paparkan di atas, optimalisasi pengawasan ketenagakerjaan merupakan hal yang menarik untuk dibahas. Oleh karena itu, penulis akan membuat kajian mengenai langkah ideal yang secara komprehensif dapat mengoptimalkan fungsi pengawasan ketenagakerjaan. Hal ini akan penulis tuangkan dalam karya tulis ilmiah yang berjudul "Penegakan Hukum Ketenagakerjaan Melalui Optimalisasi Pengawasan Guna Mewujudkan Sistem Outsourcing Berwawasan Hak Asasi Manusia”. Berdasarkan latar belakang yang telah disampaikan sebelumnya, ada beberapa masalah yang akan penulis bahas dalam karya tulis ilmiah ini. Adapun masalah tersebut adalah: pertama, bagaimana kondisi penegakan hukum ketenagakerjaan dalam bidang pengawasan saat ini; dan Kedua, bagaimana penegakan hukum ketenagakerjaan melalui optimalisasi pengawasan guna mewujudkan sistem outsourcing yang berorientasi pada Hak Asasi Manusia.

\section{B. Pembahasan}

\section{Kondisi Penegakan Hukum Ketenagakerjaan di Bidang Pengawasan}

Sebagai negara hukum, sebagaimana bunyi Pasal 1 ayat (3) Undang-Undang Dasar Negara Republik Indonesia Tahun 1945 (UUD NRI 1945), setiap aspek kehidupan bangsa Indonesia telah diatur dalam hukum positif, salah satunya ketentuan mengenai hukum ketenagakerjaan. Aturan hukum ketenagakerjaan ini diselaraskan dengan bunyi Pasal 28D ayat (2) UUD NRI 1945 yang mencerminkan bahwa tiap orang berhak atas pekerjaan, imbalan serta perlakuan yang adil dan layak dalam rangka pemenuhan kebutuhan hidupnya,.

Sistem outsourcing merupakan salah satu ketentuan yang diatur dalam hukum ketenagakerjaan. Namun, implementasi sistem ini masih menuai kontroversi. Pihak yang setuju, biasanya datang dari kalangan pengusaha, menyatakan bahwa implementasi sistem outsourcing menawarkan efisiensi biaya produksi (cost of production). Di sisi lain, pihak kontra, biasanya datang dari kalangan tenaga kerja, mengeluhkan akan belum

12 Kementerian Dalam Negeri, “Awasi Outsourcing Kemenakertrans-Kemendagri Terbitkan Peraturan”, http://www.kemendagri.go.id/news/2012/07/20/awasi-outsourcing-kemenakertrans-kemdagri-terbitkanperaturan, diakses pada 11 Oktober 2016 pukul $09.41 \mathrm{WIB}$. 
optimalnya fungsi pengawasan saat ini. Dalam menjalankan fungsi pengawasan, pengawas harus memastikan adanya fungsi pendidikan dan penegakan hukum terkait kondisi kerja. ${ }^{13}$ Implementasi pengawasan terhadap pekerja outsourcing mengacu pada Undang-Undang Nomor 1 Tahun 1970 tentang Keselamatan Kerja, Undang-Undang Nomor 7 Tahun 1981 tentang Wajib Lapor Perusahaan, Undang-Undang Nomor 24 Tahun 2011 tentang Badan Penyelenggara Jaminan Sosial, Undang-Undang Ketenagakerjaan, Undang-Undang Nomor 21 Tahun 2003 tentang Pengesahan Konvensi ILO No. 81 Mengenai Pengawasan Ketenagakerjaan Dalam Industri dan Perdagangan, Peraturan Presiden Nomor 21 Tahun 2010 tentang Pengawasan Ketenagakerjaan dan Peraturan Menteri Nomor 19 Tahun 2012 tentang Syarat-Syarat Penyerahan Sebagian Pelaksanaan Pekerjaan Kepada Perusahaan Lain. ${ }^{14}$

Berdasarkan data yang diperoleh dari Kementerian Kenetagakerjaan dan Transmigrasi, di tahun 2013 jumlah pengawas ketenagakerjaan sebanyak 2.384 orang untuk menangani sekitar 216.541 perusahaan. Sebagai agen yang aktif untuk kemajuan sosial $^{15}$, pengawas terdiri atas Pengawas Umum 1.460 orang, Pengawas Spesialis 361 orang, dan Penyidik Pegawai Negeri Sipil 563 orang. Bahkan, sebaran pengawas pada saat itu baru menjangkau lebih kurang 300 kabupaten/kota dari 500 kabupaten/kota yang ada. ${ }^{16}$ Hal tersebutlah yang turut menyebabkan belum optimalnya fungsi pengawasan, dilihat dari perbandingan jumlah antara pengawas dan perusahaan yang diawasi tidak seimbang. Muhaimin Iskandar, Menteri Tenaga Kerja dan Transmigrasi Republik Indonesia periode 2009-2014, menyatakan bahwa secara ideal seorang pengawas mengawasi 60 perusahaan tiap tahun. ${ }^{17}$ Dengan jumlah 216.541 perusahaan pada saat itu, maka dibutuhkan 3610 pengawas untuk menjalankan fungsi pendidikan dan penegakan hukum. Namun, karena jumlah yang tidak seimbang, pengawas tidak dapat menjalankan fungsi pendidikan dan penegakan hukum secara maksimal.

Sebelum diundangkannya Undang-Undang Nomor 23 Tahun 2014 tentang Pemerintahan Daerah, yang selanjutnya disebut UU Pemerintahan Daerah, implementasi

13 Program Administrasi dan Pengawasan Ketenagakerjaan ILO (International Labor Organization), "Pengawasan Ketenagakerjaan: Apa dan Bagaimana", hlm. 14.

14 Yuni Kartikasari, "Pelaksanaan Pengawasan Terhadap Perlindungan Pekerja Outsourcing: Studi Dinas Tenaga Kerja dan Transmigrai Kabupaten Kediri”, 2015, hlm. 7.

${ }^{15}$ Op. Cit., hlm. 22

16 Nur, "Pengawasan Ketenagakerjaan Harus Kembali Sentralistik", http://bisnis.liputan6.com/read/557151/pengawasan-ketenagakerjaan-harus-kembali-sentralistik, diakses pada 13 Oktober 2016 pukul 14.44 WIB

17 Ady, "Pengawasan Ketenagakerjaan Diusulkan Terpusat", http://www.hukumonline.com/berita/baca/lt5165778b75bfe/pengawasan-ketenagakerjaan-diusulkankembali-terpusat, diakses pada 13 Oktober pukul 14.56 WIB 
pengawasan ketenagakerjaan terkendala oleh sekat-sekat kebijakan otonomi daerah. Pengawasan yang demikian bermakna bahwa tiap daerah baik provinsi maupun kabupaten/kota berwenang untuk melakukan fungsi pengawasan termasuk ketenagakerjaan. Namun, Muhaimin Iskandar menyatakan bahwa pengawasan yang demikian belum optimal dalam menjalankan fungsi pendidikan dan penegakan hukum yang dibuktikan dengan tidak tercapainya indikator standar pelayanan minimal oleh pengawas. ${ }^{18}$ Dengan hadirnya UU Pemerintahan Daerah, pengawasan ketenagakerjaan dilaksanakan secara sentralistik dan wewenangnya diserahkan kepada Dinas Tenaga Kerja dan Transmigrasi tingkat provinsi. Pengawasan yang demikian diharapkan dapat tercapainya fungsi pengawasan yang independen, terpadu, terkoordinasi dan terintregrasi. $^{19}$

Dewasa ini, pengawasan ketenagakerjaan merupakan bagian penting untuk menjaga stabilitas ketenagakerjaan nasional. Namun, sarana dan prasana sebagai faktor pendukung implementasi pengawasan saat ini kurang memadai. Berdasarkan data dari Dinas Tenaga Kerja Kota Bandung, jumlah kendaraan dinas roda empat di tahun 2012 sebanyak 9 unit dengan jumlah pengawas sebanyak 14 orang. ${ }^{20}$ Perlu digarisbawahi bahwa kesembilan unit kendaraan dinas tersebut tidak sepenuhnya dialokasikan bagi pengawas di Dinas Tenaga Kerja Kota Bandung.

Bertolak dari pelbagai persoalan di atas, diperlukan suatu langkah konkret dalam penegakan hukum ketenagakerjaan melalui optimalisai pengawasan guna mewujudkan sistem outsourcing yang berorientasi pada Hak Asasi Manusia.

\section{Pengawasan Sistem Outsourcing Yang Berorientasi Pada Hak Asasi Manusia}

Tujuan utama dari setiap pengawasan ketenagakerjaan adalah memastikan kepatuhan dengan peraturan perundang-undangan yang berlaku. Berarti serangkaian standar nasional yang dirancang untuk melindungi seluruh pekerja dan bila mungkin, keluarga pekerja. ${ }^{21}$ Tercapainya tujuan pengawasan tersebut dapat menjadi indikator pelaksanaan pengawasan yang ideal.

18 Iman Rosidi, "Pengawasan Ketenagakerjaan Terkendala Kebijakan Otonomi Daerah", http://economy.okezone.com/read/2013/04/09/320/788721/pengawasan-ketenagakerjaan-terkendala-

9 Ibid kebijakan-otonomi-daerah, diakses pada 13 Oktober 2016 pukul $16.40 \mathrm{WIB}$

${ }^{20}$ Dinas Tenaga Kerja Kota Bandung, ’Rencana Strategis Dinas Tenaga Kerja Kota Bandung Tahun 2013 2018”, hlm. 20

21 Program Administrasi dan Pengawasan Ketenagakerjaan ILO (International Labor Organization), Pengawasan Ketenagakerjaan: Apa dan Bagaimana, hlm. 16. 
Idealnya suatu pengawasan dalam sistem outsourcing dilihat dari terpenuhi atau tidaknya ketentuan outsourcing yang telah dimuat dalam hukum positif. Sistem outsourcing sendiri telah menempatkan tenaga kerja pada kedudukan yang "istimewa". Hal ini dikarenakan hubungan kerja yang terjadi pada outsourcing adalah antara tenaga kerja dengan vendor $^{22}$ bukan antara tenaga kerja dengan principal.

Sebenarnya banyak kritikan terhadap sistem outsourcing ini, karena secara legal-formal principal tidak bertanggung jawab langsung terhadap pemenuhan hakhak tenaga kerja bersangkutan. ${ }^{23}$ Oleh karena itu, dalam rangka melindungi tenaga kerja yang ditempatkan tersebut ditentukan beberapa syarat untuk meminimalisasi dampak negatif dari sistem outsourcing. ${ }^{24}$

Syarat-syarat tersebut wajib dipenuhi oleh vendor maupun principal, agar tenaga kerja yang bersangkutan tetap terlindungi hak-haknya dan tidak mengalami eksploitasi secara berlebihan. ${ }^{25}$ Praktik outsourcing dalam UU Ketenagakerjaan dapat dilaksanakan dengan persyaratan yang sangat ketat sebagai berikut: ${ }^{26} 1$ ). Vendor merupakan bentuk usaha berbadan hukum dan memiliki izin dari instansi yang berwenang; 2). Tenaga kerja yang ditempatkan tidak boleh digunakan untuk melaksanakan kegiatan pokok yang berhubungan langsung dengan proses produksi; 3). Adanya hubungan kerja yang jelas antara tenaga kerja dengan vendor, sehingga tenaga kerja yang ditempatkan tersebut mendapatkan perlindungan kerja yang optimal sesuai standar minimum ketenagakerjaan; 4). Hubungan kerja harus dituangkan dalam perjanjian secara tertulis, yang memuat seluruh hak dan kewajiban para pihak sesuai dengan ketentuan peraturan perundang-undangan ketenagakerjaan; 5). Bagian pekerjaan yang dapat diserahkan kepada principal, diharuskan memenuhi syarat-syarat: (a)apabila bagian pekerjaan yang dimaksud dapat dilakukan secara terpisah dari kegiatan utama, (b). bagian pekerjaan itu merupakan kegiatan penunjang perusahaan secara keseluruhan sehingga apabila dikerjakan pihak lain tidak akan menghambat proses produksi secara langsung, dan (c). dilakukan dengan perintah langsung atau tidak langsung dari principal.

\footnotetext{
${ }^{22}$ Adrian Sutedi , Hukum Perburuhan, Jakarta: Sinar Grafik, 2009, hlm. 221.

${ }^{23}$ Ibid., hlm. 218.

${ }^{24}$ Ibid.

25 Ibid.

${ }^{26}$ Ibid., hlm. 218-221.
} 
Semua persyaratan tersebut bersifat kumulatif, sehingga bila salah satu tidak terpenuhi, bagian pekerjaan tersebut tidak dapat di-outsourcing-kan. ${ }^{27} \mathrm{Hal}$ ini supaya tenaga kerja diperlakuan sama oleh principal dan vendor untuk mencapai tujuan pengawasan ketenagakerjaan, sehingga tidak ada lagi syarat kerja, upah, dan perlindungan kerja yang rendah. ${ }^{28}$

Optimalisasi yang dilakukan untuk mewujudkan pengawasan ketenagakerjaan yang ideal, tidak terlepas dari peran pemerintah dan keaktifan tenaga kerja dalam memperjuangkan hak-hak dasarnya. Bertolak dari hal tersebut, optimalisasi pengawasan ketenagakerjaan dilihat dari dua aspek, yaitu pengawas ketenagakerjaan dan tenaga kerja.

Dilihat dari aspek pengawas ketenagakerjaan, apabila merujuk pada persoalan sebelumnya, kuantitas dan kualitas menjadi faktor utama dari lemahnya pengawasan ketenagakerjaan. Maka diperlukan optimalisai, dari segi kuantitas adalah menambah jumlah pegawai pengawas dengan merekrut sejumlah pegawai baru sesuai dengan rasio perusahaan yang akan diawasi. Sementara dari segi kualitas dengan mengadakan diklat yang mempersyaratkan materi dan pola pendidikan sesuai dengan kebutuhan dan perkembangan hukum (kognitif), serta menanamkan moral terhadap aparat penegak hukum itu sendiri (afektif).

Selain kuantitas memadai dan kualitas yang baik dari pengawas, seharusnya pemerintah turut membenahi sarana dan prasarana. Hal itu dikarenakan, sarana dan prasarana merupakan hak yang harus diperoleh pengawas, berupa kantor lokal yang dilengkapi perlengkapan, fasilitas transportasi, dan biaya perjalanan saat pengawas tersebut menjalankan tugasnya. ${ }^{29}$

Pegawai pengawas ketenagakerjaan melakukan tiga jenis pemeriksaan lapangan dalam melakukan pengawasan, ${ }^{30}$ yaitu Pertama, pemeriksaan awal yang mencakup pada aspek norma kerja, norma kesehatan dan keselamatan kerja. Pemeriksaan dilakukan dalam bentuk pembinaan dan sosialisasi yang bekerja sama dengan bidang pembinaan hubungan industrial pada awal perusahaan tersebut didirikan. Sosialisasi tersebut memberitahukan tentang bagaimana menjalankan aturan atau dasar hukum ketenagakerjaan dan adanya layanan pengaduan melalui Call Center.

${ }^{27}$ Ibid., hlm. 221.

28 Ibid.

${ }^{29}$ Lihat pasal 11 ayat (1) dan (2) Undang-Undang No. 21 Tahun 2003 tentang Pengesahan Konvensi ILO Nomor 81 mengenai Pengawasan Ketenagakerjaan dalam Industri dan Perdagangan.

${ }^{30}$ Program Administrasi dan Pengawasan Ketenagakerjaan ILO (International Labor Organization), Op. cit., hlm. 8 . 
Setelah melewati tahap pembinaan dan sosialisasi, diharapkan tenaga kerja mengetahui hak dan kewajiban, serta berbagai bentuk pelanggaran yang mungkin dilakukan oleh perusahaan dan langsung menyampaikan pengaduannya melalui layanan Call Center. Penerapan Call Center ini mengadopsi layanan pengaduan dari Badan Nasional Perlindungan dan Penempatan Tenaga Kerja Indonesia. ${ }^{31}$

Kedua, pemeriksaan berkala minimal satu tahun sekali yang pemeriksaannya secara umum sama dengan apa yang dilakukan pada pemeriksaan pertama. Ketiga, pemeriksaan khusus yaitu pemeriksaan yang dilakukan apabila ada hal-hal tertentu misalnya pengaduan.

Jika tenaga kerja khususnya tenaga kerja outsourcing merasa ada hal yang tidak sesuai dengan aturan hukum ketenagakerjaan, maka mereka dapat langsung mengadukannya melalui Call Center yang dikelola oleh Kementerian Tenaga Kerja dan Transmigrasi (Kemenakertrans) dengan menyebutkan daerah provinsi tempat ia bekerja. Kemudian, dari Kemenakertrans diintegrasikan kepada Dinas Tenaga Kerja dan Transmigrasi Provinsi (Disnakertrans Provinsi) yang bersangkutan dan memberikan keterangan lebih lanjut mengenai identitas tenaga kerja, tempat tenaga kerja tersebut bekerja atau tempat ia dipekerjakan, dalam hal ini, identitas vendor dan principal apabila yang melaporkan adalah tenaga kerja outsourcing, serta pelanggaran yang dilakukan oleh perusahaan. Dari pengaduan tersebut, pengawas ketenagakerjaan melakukan pemeriksaan khusus dan mengambil tindakan tegas bagi perusahaan yang terbukti melakukan pelanggaran. Bila diperlukan dan seringkali sebagai jalan terakhir, pengawas dapat menggunakan kekuasaannya dan mengambil tindakan penegakan hukum formal untuk mencapai kepatuhan pada undangundang. ${ }^{32}$ Dengan adanya layanan Call Center ini, tenaga kerja dapat berperan aktif dalam proses pengawasan ketenagakerjaan guna melindungi hak-hak dasar yang seharusnya diperoleh.

Pemenuhan terhadap Hak Asasi Manusia setiap orang termasuk tenaga kerja outsourcing, juga menjadi tanggung jawab negara. Hal ini sejalan dengan pendapat Arief Sidharta yang merumuskan pandangannya tentang unsur-unsur dan asas-asas Negara Hukum, salah satunya yaitu pengakuan, penghormatan, dan perlindungan

\footnotetext{
${ }^{31}$ Layanan Call $\backslash$ Ccenter Badan Nasional Perlindungan dan Penempatan Tenaga Kerja Indonesia (BNP2TKI) dimulai sejak tahun 2011. Layanan ini bertujuan untuk meningkatkan peran perlindungan dan membantu penyelesaian kasus para TKI yang ada di Indonesia dan di luar negeri.

32 Program Administrasi dan Pengawasan Ketenagakerjaan ILO (International Labor Organization), Op. cit., hlm. 18.
} 
Hak Asasi Manusia yang berakar dalam penghormatan atas martabat manusia (human dignity). ${ }^{33}$ Jadi, konsekuensi sebagai negara hukum, pemerintah bertanggungjawab atas pengakuan, penghormatan, dan perlindungan Hak Asasi Manusia tenaga kerja outsourcing.

Sepeti yang sudah dijelaskan sebelumnya, bentuk pertanggung jawaban negara dilihat dari segi hukum terbagi menjadi tiga bentuk, yaitu: duty to fulfill, dalam hal ini bentuk pertanggung jawaban negara memenuhi hak-hak dasar masyarakatnya diwujudkan dengan pembangunan sarana dan prasarana.

Adapun keterkaitan dengan pembukaan layanan Call Center, langkah tersebut merupakan salah satu upaya pemerintah dalam melaksanakan tugasnya untuk memenuhi hak-hak dasar masyarakat dengan memberikan wadah bagi tenaga kerja untuk menyampaikan keluhannya tentang kemungkinan pelanggaran terhadap hukum ketenagakerjaan yang dilakukan oleh perusahaan hingga merugikan tenaga kerja khususnya dalam implementasi sistem outsourcing. Perbaikan terhadap sarana dan prasarana bagi pengawas ketenagakerjaan juga wujud upaya negara dalam memenuhi kebutuhan guna mengoptimalkan pengawasan.

Duty to protect, merupakan pertanggung jawaban negara dalam bentuk perlindungan dan penjaminan Hak Asasi Manusia setiap orang. Dalam pelaksanaan sistem outsourcing, wujudnya adalah pemenuhan hak-hak dasar tenaga kerja melalui pengawasan yang ideal, sehingga negara dapat menunaikan tanggung jawabnya, menjamin tenaga kerja memperoleh hak-hak dasar sebagaimana yang diamanatkan dalam pasal 28 D ayat (2) UUD NRI 1945. ${ }^{34}$

Duty to respect merupakan pertanggungjawaban negara dalam bentuk penghargaan hak asasi setiap orang agar tidak terjadi tumpang tindih antar kepentingan warga negara terhadap pemenuhan hak asasinya. Sosialisasi yang benar dan tepat bagi perusahaan dan tenaga kerja merupakan langkah strategis optimalisasi pengawasan untuk memberitahukan hak dan kewajiban masing-masing pihak. Jadi, hak dan kewajiban antara perusahaan dan tenaga kerja berjalan selaras, sehingga tidak terjadi tumpang tindih maupun perlakuan semena-mena dari pihak yang lebih kuat kepada pihak yang lemah. Hakikatnya Hak Asasi Manusia

\footnotetext{
${ }^{33}$ Arief Sidharta, Kajian Keefisienan tentang Negara Hukum, dalam Jentera (Jurnal Hukum), Rule of Law, Pusat Studi Hukum dan Kebijakan (PSHK), Jakarta, edisi 3 Tahun II, November 2004, hlm. 124-125.

${ }^{34}$ Lihat Pasal 28 D ayat (2) Undang-Undang Dasar Negara Republik Indonesia Tahun 1945 "Setiap orang berhak untuk bekerja serta mendapat imbalan dan perlakuan yang adil dan layak dalam hubungan kerja".
} 
merupakan hak pemberian Tuhan Yang Maha Esa kepada setiap orang, oleh karena itu harus dihormati dan dihargai.

\section{Simpulan}

Dari keseluruhan pembahasan tersebut maka dapat disimpulakan bahwa Pertama, penegakan hukum ketenagakerjaan belum optimal. Hal tersebut diketahui dari masih adanya persoalan-persoalan yang terjadi antara lain tidak adanya jaminan sosial, upah yang sangat rendah dan penempatan tenaga kerja outsourcing yang tidak sesuai dengan peraturan perundang-undangan menjadikan tenaga kerja outsourcing kehilangan hak-hak dasarnya. Kedua, upaya optimalisasi pengawasan sistem outsourcing yang berorientasi pada Hak Asasi Manusia dapat dilakukan melalui penegakan hukum ketenagakerjaan terpadu.

Pengawasan sistem outsourcing harus menekankan pada perlindungan (to protect), pemenuhan (to fulfill), dan penghormatan (to respect) agar lebih optimal. Oleh karena itu, diperlukan langkah konkret dalam penegakan hukum ketenagakerjaan. Salah satunya dengan pembentukan call center khusus pengaduan yang terpusat di Kementerian Ketenagakerjaan dan terintegrasi dengan Dinas Tenaga Kerja dan Transmigrasi tingkat provinsi. Call center ini melayani pengaduan atas terjadinya pelanggaran dan diharapkan dapat meningkatkan kinerja pengawas ketenagakerjaan. Dengan adanya sistem outsourcing dalam hukum ketenagakerjaan, pemenuhan Hak Asasi Manusia bagi tenaga kerja tetap terpenuhi.

\section{Daftar pustaka}

Adrian Sutedi, "Hukum Perburuhan, Jakarta: Sinar Grafika, 2009.

Ady, "Pengawasan Ketenagakerjaan Diusulkan Kembali Terpusat", http://www.hukumonline.com/berita/baca/lt5165778b75bfe/pengawasan-

ketenagakerjaan-diusulkan-kembali-terpusat, diakses pada 13 Oktober pukul 14.56 WIB

Agusmidah dkk, Bab-Bab Tentang Hukum Perburuhan Indonesia, Denpasar: Pustaka Larasan; Jakarta: Universitas Indonesia; Universitas Leiden; Universitas Groningen, 2012.

Arief Sidharta, Kajian Keefisienan tentang Negara Hukum, dalam Jentera (Jurnal Hukum), Rule of Law, Pusat Studi Hukum dan Kebijakan (PSHK), Jakarta, edisi 3 Tahun II, November 2004, hlm. 124-125.

Dinas Tenaga Kerja Kota Bandung, "Rencana Strategis Dinas Tenaga Kerja Kota Bandung Tahun 2013 - 2018".

Iman Rosidi, "Pengawasan Ketenagakerjaan Terkendala Kebijakan Otonomi Daerah", http://economy.okezone.com/read/2013/04/09/320/788721/pengawasanketenagakerjaan-terkendala-kebijakan-otonomi-daerah, diakses pada 13 Oktober 2016 pukul 16.40 WIB 
Kementerian Dalam Negeri, "Awasi Outsourcing Kemenakertrans-Kemendagri Terbitkan Peraturan”, $\quad$ http://www.kemendagri.go.id/news/2012/07/20/awasi-outsourcingkemenakertrans-kemdagri-terbitkan-peraturan, diakses pada 11 Oktober 2016 pukul 09.41 WIB.

Layanan Call \Ccenter Badan Nasional Perlindungan dan Penempatan Tenaga Kerja Indonesia (BNP2TKI) dimulai sejak tahun 2011. Layanan ini bertujuan untuk meningkatkan peran perlindungan dan membantu penyelesaian kasus para TKI yang ada di Indonesia dan di luar negeri.

Nur, "Pengawasan Ketenagakerjaan Harus Kembali Sentralistik", http://bisnis.liputan6.com/read/557151/pengawasan-ketenagakerjaan-harus-kembalisentralistik, diakses pada 13 Oktober 2016 pukul 14.44 WIB

Peraturan Menteri Tenaga Kerja dan Transmigrasi Nomor 19 Tahun 2012 tentang SyaratSyarat Penyerahan Sebagian Pelaksanaan Pekerjaan Kepada Peusahaan Lain.

Program Administrasi dan Pengawasan Ketenagakerjaan ILO (International Labor Organization), "Pengawasan Ketenagakerjaan: Apa dan Bagaimana",

Raisa Adila, "Menteri Hanif Serius Tangani Outsourcing di BUMN", http://economy.okezone.com/read/2015/06/24/320/1170781/menteri-hanif-seriustangani-outsourcing-di-bumn, diakses pada 11 Oktober pukul 1.17 WIB.

Siprianus Edi Hardum, "Sistem Kerja Outsourcing Perlu Pengawasan Ketat", http://sp.beritasatu.com/ekonomidanbisnis/sistem-kerja-outsourcing-perlupengawasan-ketat/24402, diakses pada 11 Oktober 2016 pukul 08.37 WIB.

Susilo Andi Darma, Kajian Hukum Ketenagakerjaan Terhadap Peraturan Menteri Tenaga Kerja dan Transmigrasi Nomor 19 Tahun 2012”, Volume 26, Tahun 2014,

Undang- Undang Nomor 13 Tahun 2003 tentang Ketenagakerjaan.

Undang-Undang Dasar Negara Republik Indonesia Tahun 1945 "Setiap orang berhak untuk bekerja serta mendapat imbalan dan perlakuan yang adil dan layak dalam hubungan kerja".

Undang-Undang No. 21 Tahun 2003 tentang Pengesahan Konvensi ILO Nomor 81 mengenai Pengawasan Ketenagakerjaan dalam Industri dan Perdagangan.

Yuni Kartikasari, "Pelaksanaan Pengawasan Terhadap Perlindungan Pekerja Outsourcing: Studi Dinas Tenaga Kerja dan Transmigrai Kabupaten Kediri”, 